Article

\title{
Multidiscipline Integrated Platform Based on Probabilistic Analysis for Manufacturing Engineering Processes
}

\author{
Lijun Zhang ${ }^{1, *} \mathbb{B}^{\mathbb{D}}$, Kai Liu ${ }^{1}$ and Jian Liu ${ }^{2, *}$ \\ 1 National Center for Materials Service Safety, University of Science and Technology Beijing, \\ Beijing 100083, China; ustbliukai@sina.com \\ 2 School of Civil and Resource Engineering, University of Science and Technology Beijing, \\ Beijing 100083, China \\ * Correspondence: ljzhang@ustb.edu.cn (L.Z.); anyonell@126.com (J.L.); \\ Tel.: +86-10-6232-1017 (L.Z.); +86-10-6233-2902 (J.L.)
}

Received: 2 July 2018; Accepted: 25 July 2018; Published: 30 July 2018

\begin{abstract}
Researchers from different disciplines, such as materials science, computer science, safety science, mechanical engineering and controlling engineering, have aimed to improve the quality of manufacturing engineering processes. Considering the requirements of research and development of advanced materials, reliable manufacturing and collaborative innovation, a multidiscipline integrated platform framework based on probabilistic analysis for manufacturing engineering processes is proposed. The proposed platform consists of three logical layers: The requirement layer, the database layer and the application layer. The platform is intended to be a scalable system to gradually supplement related data, models and approaches. The main key technologies of the platform, encapsulation methods, information fusion approaches and the collaborative mechanism are also discussed. The proposed platform will also be gradually improved in the future. In order to exchange information for manufacturing engineering processes, scientists and engineers of different institutes of materials science and manufacturing engineering should strengthen their cooperation.
\end{abstract}

Keywords: probabilistic analysis; manufacturing engineering process; materials database; multidiscipline integrated platform; information fusion

\section{Introduction}

Higher demands of manufacturing engineering processes are expected with the rapid development of an advanced manufacturing industry. In recent years, increasingly advanced materials, structures and equipment have enhanced the safety and reliability of manufacturing engineering processes. In addition, researchers from different disciplines, such as materials science, computer science, safety science, mechanical engineering and controlling engineering, have aimed to improve the quality and reliability of manufacturing engineering processes.

However, the "languages" of different disciplines are varied. For instance, the gap between materials science and manufacturing engineering remains large, requiring that scientists and engineers attempt to solve this problem. The materials database is a bridge between materials science and manufacturing engineering, and such materials databases for different industrial fields have been established [1-3]. However, most databases are built only by scientists and engineers of materials science or manufacturing engineering. Therefore, how to plan and build a platform that can be widely applied to the manufacturing process has become a state-of-the-art issue during the past decade. In 2008, a new and promising engineering approach known as integrated computational materials 
engineering (ICME) emerged [4]. Its goal was to enable the optimization of materials, manufacturing processes, and component design long before components are fabricated. After ICME, the concept of integrated computational materials and manufacturing engineering $\left(\mathrm{ICM}^{2} \mathrm{E}\right)$ was also proposed. Furthermore, in 2011, the materials genome initiative (MGI) was announced by President Obama's government in the United States of America. In general, these technologies make full use of data platforms and numerical simulation, providing new research directions for materials science and manufacturing engineering.

In recent years, the new era of big data and Industry 4.0 for manufacturing engineer processes has arrived $[5,6]$. Therefore, the full integration of various data, models, and knowledge in manufacturing engineering processes is very important for both theoretical research and engineering application. Some works now in development in commercial software inspired by Industry 4.0 are [7] and the linked work in [8], which both provide the whole approach and examples. Based on this, several works have applied advances, such as [9]. Other ideas are now in practice in Europe, including the well-known example of the Aeronautics Advanced Manufacturing Centre (CFAA) in Spain [10].

In addition to building a unified integration platform, the corresponding analysis methods and models also play an important role in the manufacturing process. Due to the development of future Internet technology, more data can be obtained from the experimental system and the industrial system. How to use the data in the platform for modeling is an important challenge. Ghahramani systematically discussed the framework and progress of probabilistic machine learning and artificial intelligence in [11]. In the current paper, a multidiscipline integrated platform framework based on probabilistic analysis for manufacturing engineering processes will be proposed. Key technologies of the proposed platform are also provided in this paper. The platform can be used to develop new models of probabilistic analysis of manufacturing engineering processes for scientists and engineers of multi-disciplines.

This paper is organized as follows. Section 2 will summarize the requirements and the challenges of manufacturing engineering processes. The basic platform framework based on probabilistic analysis will be introduced in Section 3. Key technologies will be analyzed in Section 4. Section 5 will illustrate an application case. Finally, conclusions will be drawn at Section 6.

\section{Requirements and Challenges of Manufacturing Engineering Processes}

\subsection{Requirements of Manufacturing Engineering Processes of Advanced Materials}

With the development of manufacturing engineering processes with advanced materials, the traditional pattern of research and development is no longer a requirement $[12,13]$. Thus, from the view of academic research and industrial application, the requirements of manufacturing engineering processes are required to follow four aspects:

(1) Integration of full lifetime cycle data of advanced materials. Currently, new materials are being developed for manufacturing engineering processes. These new materials have different properties and are being improved at a declining price. From the materials' design to their service, the typical process of an advanced material's life may be divided into several parts, as shown in Figure 1. In order to establish a traceability mechanism for advanced materials, all data of different processes should be integrated and shared with the authorized institutes.

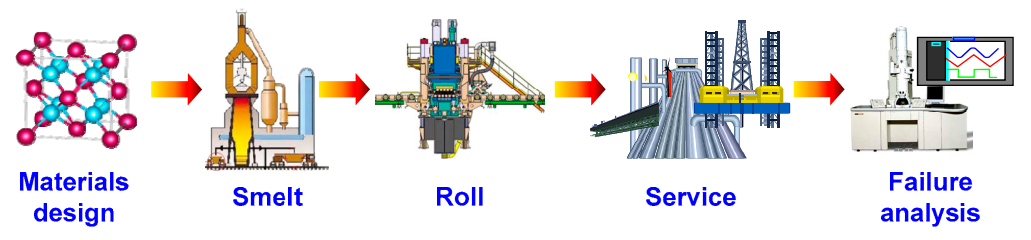

Figure 1. Typical process diagram of an advanced material's life. 
(2) Numerical simulation development of materials research. Significant manpower and material resources used in repeated experiments are wasted. To reduce the development cost and shorten the development time for advanced materials, the use of numerical simulation experiments is rising [14], although such experiments are nonetheless based on physical simulation experiments and digital data. Figure 2 shows a flowchart of a material's life cycle with experimental tools, digital data and computational tools.

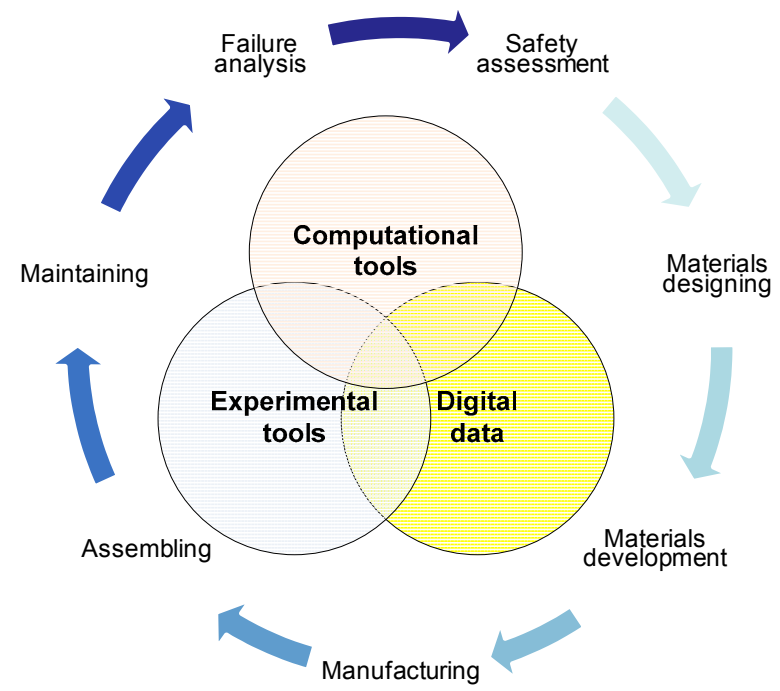

Figure 2. Flowchart of a material's life cycle with experimental tools, digital data and computational tools.

(3) Opening and sharing services for safety and reliability of manufacturing engineering processes. As most manufacturing engineering is a process industry system, the failure of one component may cause the interruption of the whole manufacturing engineering process. However, lack of prior knowledge of failure modes and probability, limits the improvement of safety and reliability for manufacturing engineering. Manufacturing engineering directly reflects the level of a country's productivity, which is an important factor to distinguish between developing countries and developed countries [15]. In order to provide opening and sharing services to public users, the new concept of cloud manufacturing $[16,17]$ also aims to promote manufacturing with dispersed resources.

(4) Requirement of collaborative innovation for manufacturing engineering processes. In manufacturing engineering, problems from different disciplines are integrated [18-20]. To achieve novel results, a multidiscipline platform should be established. From the development trends of modern science and technology, significant achievements are coming increasingly from multidiscipline collaborative innovation [21]. Figure 3 demonstrates a logical diagram of a multidiscipline integrated platform for collaborative innovation. From Figure 3, the experimental resource, the computational resource, the private storage resource and the public cloud resource are integrated. The collaborative innovation strategy for manufacturing engineering processes is presented for researchers of materials science and manufacturing engineering. 


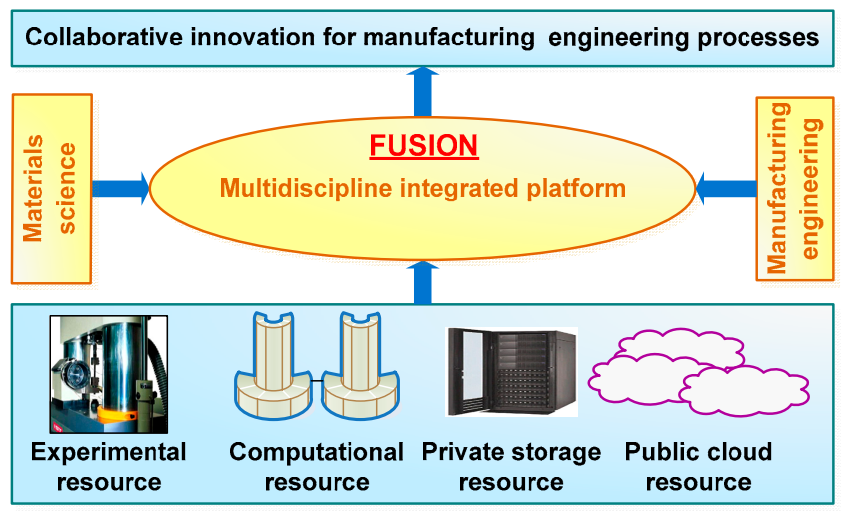

Figure 3. Logical diagram of a multidiscipline platform for collaborative innovation.

\subsection{Main Challenges of Manufacturing Engineering Processes}

Based on the above review and analysis of manufacturing engineering processes, the present research still faces the following challenges:

(1) Current materials databases are mostly dispersed, and especially lack life cycle data for materials science and manufacturing engineering. The quality of existing data is not certain. Materials data may not be able to be directly applied to actual applications. Users of materials databases may be confused by the fact that the data are unreliable and incomplete. In addition, data providers would rather share "bad" data than "good" data with others because of a conflict of interest. For instance, accessing original materials data to assess the service safety of a gathering pipeline may not be straightforward. The result of a safety assessment for a pipeline may be questionable.

(2) As the research processes and approaches of different disciplines vary greatly, knowledge of different disciplines is hardly exchanged or shared without a unified multidiscipline platform. In a complex manufacturing engineering process, equipment and products constitute a multidiscipline system. Current data and models for manufacturing engineering processes are not sufficient to design and assess. In most institutes or companies, researchers or engineers are separated by different disciplines, so that a researcher of materials science cannot directly talk to an engineer of manufacturing engineering processes. In addition, there is also a gap between an IT (information technology) engineer and a mechanical engineer.

\section{Basic Platform Framework Based on Probabilistic Analysis}

\subsection{Probabilistic Analysis Approaches for Engineering Materials}

In manufacturing engineering processes, we use deterministic design approaches and probabilistic design approaches [22]. Traditional design assumes most input parameters are deterministic. However, uncertainty exists in different parameters, such as material properties, manufacturing processes and mechanical loads.

However, manufacturing data can be lacking, and we do not know the input probability distribution. We can use the best engineering assessments from literature, handbooks and experience. Thus, an integrated platform with more data and more failure cases is needed. In addition, related approaches to probabilistic analysis, such as Monte Carlo analysis, the first-order reliability method (FORM), the second-order reliability method (SORM), response surface methods (RSM), and probabilistic fault tree analysis (PFTA), should be integrated in the platform. User-defined methods of probabilistic analysis should also be integrated for future application. The platform should be considered together with the related knowledge of manufacturing engineering. 


\subsection{Framework of Multidiscipline Integrated Platform for Manufacturing Engineering Processes}

As can be seen from the previous analysis, more data, information and knowledge should be integrated into the manufacturing engineering process. Therefore, the architecture of the framework of a multidiscipline integrated platform is particularly important. The multidiscipline platform can be divided into three layers-the requirement layer, the database layer and the application layer-for manufacturing engineering processes, as shown in Figure 4. In this functional figure, we try to mix human experts with computer systems. The architecture of the proposed framework is similar to the smart manufacturing system $[23,24]$.

The first layer is the requirement layer. The underlying requirement layer comes from materials designers, manufacturing engineers and also materials service safety experts. As a "middle man", an expert of materials service safety will provide the communication bridge between materials designers and manufacturing engineers. More data and algorithms of system engineering would also be used by materials service safety experts. The Internet of Things [25,26] and cloud computing [27] may also provide a more comprehensive method of data acquisition for condition monitoring of manufacturing engineering. In this layer we can integrate different requirements for materials designers, manufacturing engineers and materials service safety experts.

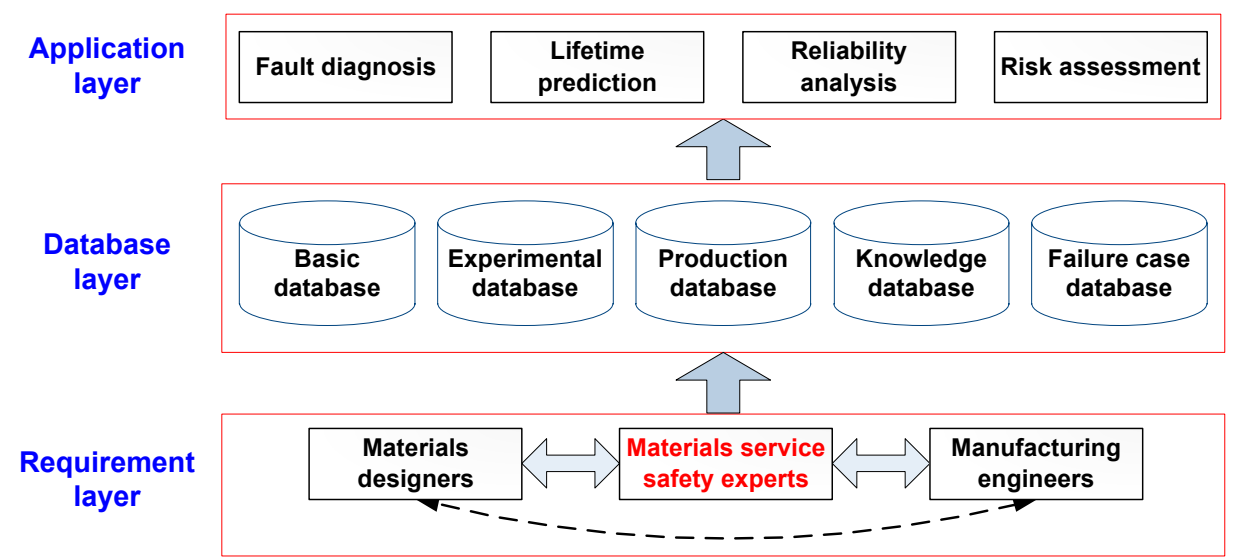

Figure 4. Architecture of a multidiscipline integrated platform for manufacturing engineering processes.

The second layer is the database layer. For the requirement of reliable manufacturing with advanced materials, the database layer contains the basic database, the experimental database, the production database, the knowledge database and the failure case database. These databases will cover the research and development for materials science and manufacturing engineering. Thus, the challenge of dispersed databases could be overcome.

The third layer is the application layer. Based on the previous two layers, the final application of the platform will mainly contain four aspects: Fault diagnosis, lifetime prediction, reliability analysis and risk assessment for manufacturing engineering. In this layer, more quantitative methods have begun to be studied in depth, replacing qualitative methods [28]. Related application services can also be acquired by various terminals. In this layer, we try to solve the dilemma of common problems or personality problems in the multidiscipline platform.

\section{Key Technologies of Multidiscipline Integrated Platform}

From the requirements of the multidiscipline integrated platform, more issues should be widely recognized relating to the following key technologies:

(1) Monitoring technology from the industrial processes. Monitoring processes is the key to improving processes previously optimized by modeling. Monitoring would help to fine-tune the window parameters in high-added value production. However, if the real recorded values 
are not related to the exact point of the process in which damage, risk or a non-conformity may happen, useful information would be missed. ANN (artificial neural networks) can correlate any variable, therefore it is of paramount importance to define the experimental data and to use a sound method. A good instance is a duo of studies, the first providing the physical results [29], and the second providing the tool and procedure [30], as it is applied in [31]. As can be seen, almost 14 years passed from the gathering of experimental values to the current application of AI (artificial intelligence) tools.

(2) Integration and encapsulation for probabilistic analysis models. The proposed platform includes related data and models for reliable manufacturing. Models of different disciplines should be integrated and encapsulated to Web services via XML (extensible markup language). Considering security, Web services could be shared with remote users with authorization, as shown in Figure 5.

In order to assess the reliability and the risk for engineering materials and manufacturing engineering, probabilistic analysis models (such as a generative model, a discriminative model, a hidden Markov model or a maximum entropy model), should be established in the actual system. A user-defined model can also be integrated into probabilistic analysis models via a standard interface.

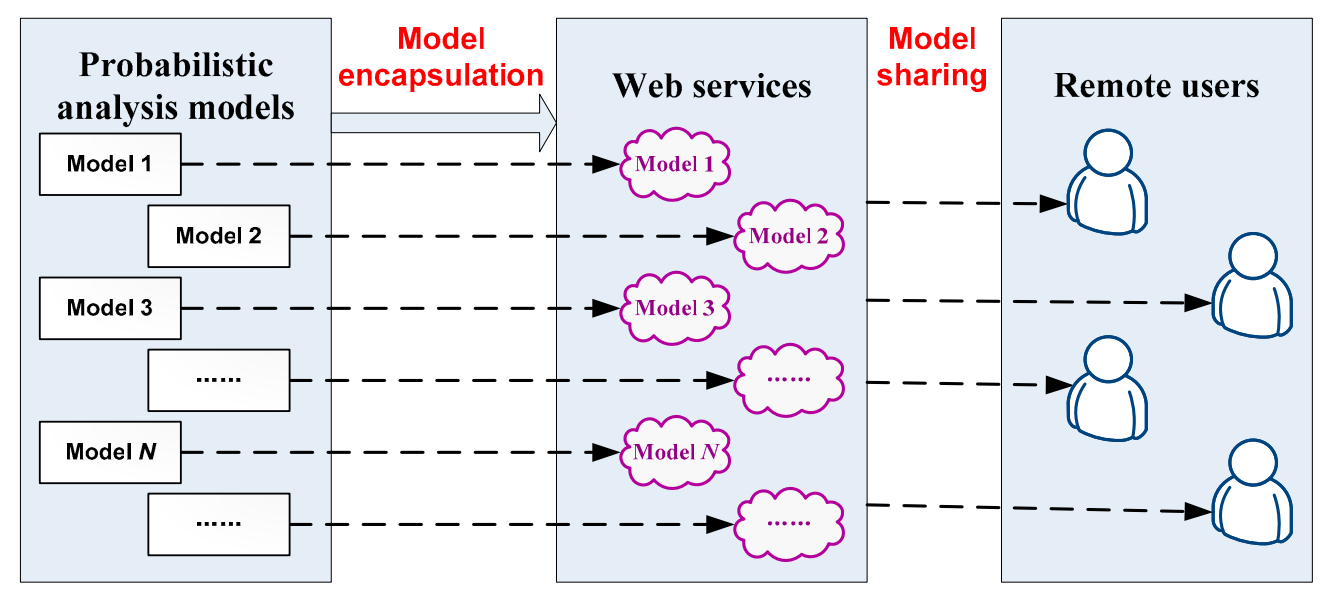

Figure 5. Schematic diagram of model encapsulation and sharing.

If the cloud computing pattern is used in the platform, information sharing will become more convenient [32]. Remote users are able to use the required services without concern about the services' providers. Moreover, public cloud services can increasingly be obtained at a low price, or even for free, at present.

(3) Information fusion approaches [33] for the multisource data. In the platform, significant quantities of data, including materials data and manufacturing data, are integrated. From the view of mathematical modeling, data are homogeneous or heterogeneous. Information fusion for homogeneous data, such as vibration data, acoustic emission data and temperature data, can be achieved using the Laplacian spectra analysis approach. Information fusion for heterogeneous data, such as vibration data and images, can be a perspective transformation. Finally, we can use the D-S (Dempster-Shafer) evidence theory to make decisions for reliable manufacturing. We should also consider analysis of the data and the problem using the compatible information approach. Figure 6 shows a multisource information fusion diagram for homogeneous signals and heterogeneous data. With the trend of big data analysis, more spatiotemporal models using data mining approaches can be introduced into the proposed platform. 


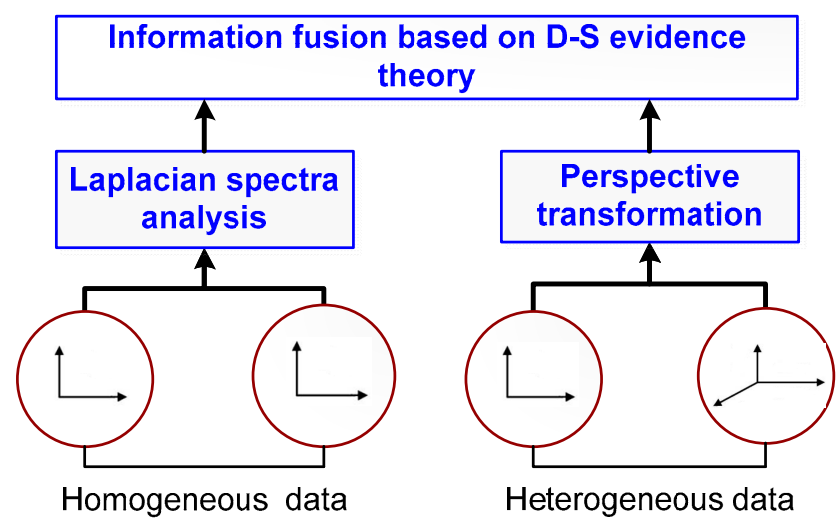

Figure 6. Multisource information fusion diagram for homogeneous signals and heterogeneous data.

(4) Technical description of platform implementation. In the proposed platform in this paper, it is necessary to integrate basic data, experimental data and industrial data. In order to ensure system compatibility and scalability, the system should adopt a language supported by cross-platform technology. The B/S (browser/service) mode is used for the end user, and is mainly used to support the dynamic expansion of the model. The main development languages of the platform are recommended as in Table 1.

Table 1. Development languages in proposed multidiscipline integrated platform.

\begin{tabular}{ccc}
\hline & Language & Comments \\
\hline For developer & Java & Support for cross-platform integration \\
For end user & Python & Support for model development \\
\hline
\end{tabular}

In addition, the scalability of the proposed platform is very important. The scalability of this platform includes the scalability of functional modules, algorithms and data. In this platform, we focus on the scalability of algorithms. Each algorithm has its scope of application, and the algorithm is constantly improving or used in combination with other algorithms. In scalable applications of algorithms, SOA (service-oriented architecture) is recommended. It allows users to package and dynamically adjust algorithms of different granularity to support the continuous expansion of the future platform. By so doing, all the above mentioned probabilistic analysis methods can be implemented and integrated for future applications.

\section{Application Case}

In 2007, a national project in China named the Materials Service Safety Assessment Facility (MSAF) was proposed by the University of Science and Technology Beijing. The purpose of establishing the MSAF was to understand the key scientific issues in materials service safety (i.e., scientific problems in scale, environment and time dimensions, as well as methods of service safety assessment). The MSAF contained six large-scale physical testing facilities, one experimental simulation system and one IT facility for opening and sharing [34].

During the past 10 years, we have established multiple platforms in the fields of petrochemical engineering, metallurgy, electric power and urban infrastructure, integrated corresponding basic data and experimental data, and have successfully applied these in some enterprises. The following is an application case of petrochemical engineering. 


\subsection{Requirement Description}

According to the needs of a petrochemical enterprise, the platform is designed to: (1) Collect and collate the actual working conditions, test and design data from multiple enterprises and research institutes, and establish a safety assessment system for key materials; (2) complement the tests (including relevant parameters and conditions); and, (3) integrate the original data and supplement the test data to lay the foundation for the safety assessment and post-assessment of key materials. The specific business flowchart of the petrochemical platform is shown in Figure 7.

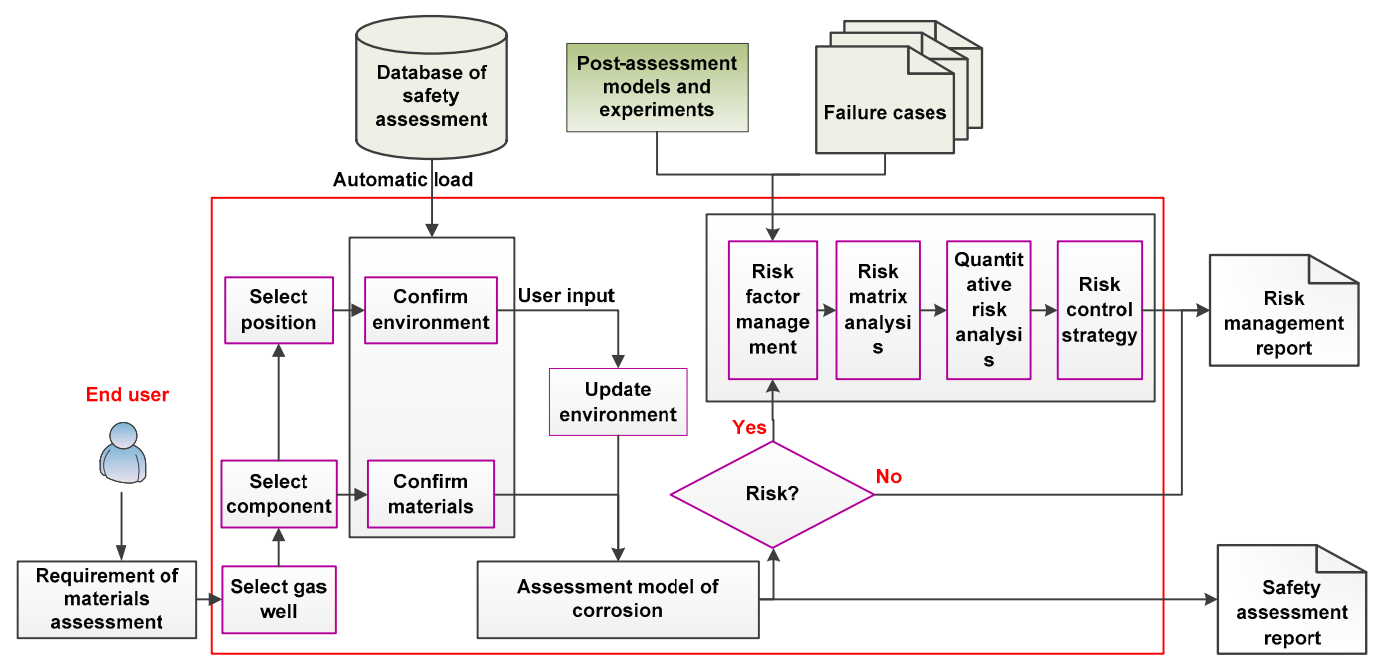

Figure 7. Business flowchart of petrochemical platform.

\subsection{Platform Application Effect}

According to the actual service environment and on-site requirements of petrochemical enterprises, the service platform of key materials, the post-evaluation criteria and safety assessment model of the supplementary and accelerated tests, and the safety assessment and risk management system were carried out. Based on the application framework proposed in this paper, the following functions are mainly completed in the petrochemical platform:

(1) Established a petrochemical material service that can realize multi-user sub-rights and scalable network data management through integration of service conditions, test data, production process data, corrosion monitoring data and literature data.

(2) Constructed a production data management system for petrochemical enterprises that can realize real-time monitoring of on-site data, and real-time monitoring and analysis of corrosion monitoring data.

(3) Developed the safety assessment and risk management system of key materials, which realized the evaluation of the risk of corrosion cracking in petrochemical enterprises, and provided support for the formulation of risk control strategies.

At present, the research results have been applied to the production of a petrochemical enterprise to protect the safety of production.

\section{Conclusions}

In this paper, we review the main requirements and challenges of reliable manufacturing with advanced materials and propose a multidiscipline integrated platform based on probabilistic analysis for manufacturing engineering processes.

(1) The multidiscipline integrated platform framework of manufacturing engineering processes is presented based on the reviewed requirements. The platform is divided into three layers: 
The requirement layer, the database layer and the application layer. The platform is designed as a scalable system to gradually supplement the related data and models.

(2) The main key technologies of the platform are discussed in this paper. In our view, the technical problems are integration and encapsulation for probabilistic analysis models, and information fusion approaches for the multisource data. Cooperation between the related institutes of materials science and manufacturing should also be strengthened.

(3) We propose the platform framework for manufacturing engineering. An application case of petrochemical engineering is presented as the implementation of this architecture of a multidiscipline integrated platform. The research results are applied to the production of a petrochemical enterprise to protect the safety of production. The platform will be gradually improved.

(4) In the future, the continuous development of future Internet technology means the platform of the manufacturing process will be more intelligent. Digital twins [35] technology may be an important research direction in this field. At present, we have engaged research work on key technologies for wind power and nuclear power related platforms, and we hope to obtain better theoretical and application results.

Author Contributions: Conceptualization, L.Z.; Data curation, K.L.; Software, K.L.; Visualization, J.L.; Writing—original draft, L.Z.; Writing—review and editing, J.L.

Funding: This work was financially supported by the National Key Research and Development Program of China (No. 2016YFF0203800), the Fundamental Research Funds for Central Universities of China (No. FRF-BD-18-001A) and the National Natural Science Foundation of China (No. 51775037).

Acknowledgments: The authors would like to express our warmest gratitude to Koichi Yagi for his instructive suggestions and valuable comments on the research work. The authors would like to thank the anonymous reviewers for their valuable comments and suggestions that helped improve the quality of this manuscript.

Conflicts of Interest: The authors declare no conflict of interest.

\section{References}

1. Morcilo, M.; Chico, B.; Diaz, I.; Cano, H.; Fuente, D.D.L. Atmospheric corrosion data of weathering steels. A review. Corros. Sci. 2013, 77, 6-24. [CrossRef]

2. $\quad$ Li, X.G.; Zhang, D.W.; Liu, Z.Y.; Li, Z.; Du, C.; Dong, C. Share corrosion data. Nature 2015, 527, 441-442. [CrossRef] [PubMed]

3. Li, Y.; Hu, C. Process materials scientific data for intelligent service using a dataspace model. Data Sci. J. 2016, 15, 7. [CrossRef]

4. Allison, J. Integrated computational materials engineering: A perspective on progress and future steps. JOM 2011, 63, 15-18. [CrossRef]

5. Reis1, M.S.; Gins, G. Industrial process monitoring in the big data/Industray 4.0 era: From detection, to diagnosis to prognosis. Processes 2017, 5, 35. [CrossRef]

6. Pilloni, V. How data will transform industrial processes: Crowdsensing, crowdsourcing and big data as pillars of Industry 4.0. Future Internet 2018, 10, 24. [CrossRef]

7. Lacalle, L.N.L.; Lamikiz, A.; Sánchez, J.A.; Bustos, I.F. Recording of real cutting forces along the milling of complex parts. Mechatronics 2006, 16, 21-32. [CrossRef]

8. Lacalle, L.N.L.; Lamikiz, A.; Sánchez, J.A.; Fernández de Bustos, I. Simultaneous measurement of forces and machine tool position for diagnostic of machining tests. IEEE Trans. Instrum. Meas. 2005, 54, 2329-2335. [CrossRef]

9. Gajate, A.; Haber, R.; del Toro, R.; Vega, P.; Bustillo, A. Tool wear monitoring using neuro-fuzzy techniques: A comparative study in a turning process. J. Intell. Manuf. 2012, 23, 869-882. [CrossRef]

10. Calleja-Ochoa, A.; Gonzalez-Barrio, H.; Polvorosa-Teijeiro, R.; De La Calle Marcaide, L.N.L. Multitasking machines: Evolution, resources, processes and scheduling. DYNA 2017, 92, 637-642. [CrossRef]

11. Ghahramani, Z. Probabilistic machine learning and artificial intelligence. Nature 2015, 521, 452-459. [CrossRef] [PubMed]

12. Wuest, T.; Weimer, D.; Irgens, C.; Thoben, K.D. Machine learning in manufacturing: Advantages, challenges, and applications. Prod. Manuf. Res. 2016, 4, 23-45. [CrossRef] 
13. El-Khasawneh, B.S. Challenges and remedies of manufacturing enterprises in developing countries: Jordan as a case study. J Manuf. Technol. Manag. 2012, 23, 328-350. [CrossRef]

14. Komoto, H.; Mishima, N.; Tomiyama, T. An integrated computational support for design of system architecture and service. CIRP Ann. Manuf. Technol. 2012, 61, 159-162. [CrossRef]

15. Ovanessoff, A.; Purdy, M. Global competition 2021: Key capabilities for emerging opportunities. Strategy Leadersh. 2011, 39, 46-55. [CrossRef]

16. Tao, F.; Cheng, Y.; Xu, L.D.; Zhang, L.; Li, B.H. CCIoT-CMfg: Cloud computing and Internet of Things-based cloud manufacturing service system. IEEE Trans. Ind. Inform. 2014, 10, 1435-1442. [CrossRef]

17. $\mathrm{Xu}, \mathrm{X}$. From cloud computing to cloud manufacturing. Robot. Comput. Integr. Manuf. 2012, 28, 75-86. [CrossRef]

18. Lee, H.J.; Lee, J.W.; Lee, J.O. Development of Web services-based multidisciplinary design optimization framework. Adv. Eng. Softw. 2009, 40, 176-183. [CrossRef]

19. Zadeh, P.M.; Shirazi, M.S. Multidisciplinary design optimization architecture to concurrent design of satellite systems. Part G J. Aerosp. Eng. 2017, 231, 1898-1916. [CrossRef]

20. Sharma, M.; Kodali, R. Validity and reliability of proposed framework of manufacturing excellence in the Indian industry. Prod. Plan. Control 2012, 23, 333-353. [CrossRef]

21. Feng, B.; Ma, J.A.; Fan, Z.P. An integrated method for collaborative R\&D project selection: Supporting innovative research teams. Expert Syst. Appl. 2011, 38, 5532-5543. [CrossRef]

22. Trombe, P.J.; Pinson, P.; Madsen, H. A General probabilistic forecasting framework for offshore wind power fluctuations. Energies 2012, 5, 621-657. [CrossRef]

23. Kusiak, A. Smart manufacturing. Int. J. Prod. Res. 2018, 56, 508-517. [CrossRef]

24. Kang, H.S.; Lee, J.Y.; Choi, S.; Kim, H.; Park, J.H.; Son, J.Y.; Kim, B.H.; Noh, S.D. Smart manufacturing: Post research, present findings, and future directions. Int. J. Precis. Eng. Manuf. Gr. Technol. 2016, 3, 111-128. [CrossRef]

25. Xu, X.; Chen, T.; Minami, M. Intelligent fault prediction system based on internet of things. Comput. Math. Appl. 2012, 64, 833-839. [CrossRef]

26. Wang, S.C.; Chen, C.W.; Wang, S.S.; Yan, K.Q. Enhancing data credibility by a lightweight security mechanism underlying the framework of the internet of things. ScienceAsia 2014, 40, 16-21. [CrossRef]

27. Zhang, W.; Yang, M.; Zhang, X.; Shi, H. OMIGG: An overlay multicast infrastructure based on cloud computing for streaming media data distribution. ScienceAsia 2016, 42, 56-63. [CrossRef]

28. Cui, L.; Huang, J.; Zhang, F. Quantitative and localization diagnosis of a defective ball bearing based on vertical-horizontal synchronization signal analysis. IEEE Trans. Ind. Electron. 2017, 64, 8695-8705. [CrossRef]

29. López de Lacalle, L.N.; Lamikiz, A.; Sánchez, J.; Salgado, M.A. Effects of tool deflection in the high-speed milling of inclined surfaces. Int. J. Adv. Manuf. Technol. 2004, 24, 621-623. [CrossRef]

30. Arnaiz-González, Á.; Fernández-Valdivielso, A.; Bustillo, A.; López de Lacalle, L.N. Using artificial neural networks for the prediction of dimensional error on inclined surfaces manufactured by ball-end milling. Int. J. Adv. Manuf. Technol. 2016, 83, 847-859. [CrossRef]

31. Abdul-lateef Al-Abdullah, K.I.; Abdi, H.; Lim, C.P.; Yassin, W.A. Force and temperature modelling of bone milling using artificial neural networks. Measurement 2018, 116, 25-37. [CrossRef]

32. Zhang, L.; Zhang, W.; Mu, N.; Zhang, B. Research on development of reliability assessment platform for engineering structural materials. In Proceedings of the 3rd Asian Materials Data Symposium, Naha, Japan, 15-18 April 2012; pp. 117-122.

33. Hillis, J.M.; Ernst, M.O.; Banks, M.S.; Landy, M.S. Combining sensory information: Mandatory fusion within, but not between, senses. Science 2002, 298, 1627-1630. [CrossRef] [PubMed]

34. Sun, D.; Zhang, L.; Shi, P.; Zhang, W.; Feng, Q. Materials data sharing and service safety assessment platform in MSAF. In Proceedings of the 2nd Asian Materials Data Symposium, Sanya, China, 10-14 March 2010; pp. 46-49.

35. Tao, F.; Cheng, J.F.; Qi, Q.L.; Zhang, M.; Zhang, H.; Sun, F.Y. Digital twin-driven product design, manufacturing and service with big data. Int. J. Adv. Manuf. Technol. 2018, 94, 9-12. [CrossRef]

(C) 2018 by the authors. Licensee MDPI, Basel, Switzerland. This article is an open access article distributed under the terms and conditions of the Creative Commons Attribution (CC BY) license (http:/ / creativecommons.org/licenses/by/4.0/). 